\title{
Spontaneously Adsorbed Mo Layers on Pt(111) and Pt(100) Single Crystal Electrode Surfaces
}

\author{
Yoongu Han, Changhoon Jung, and Choong Kỵun Rhee* \\ Department of Chemistry: Chungnam National Lniversitw, 220 Kung-dong, Husung-ku, Teajun 305-764, Korea \\ Recerved October $\mathrm{t}_{1} 2001$
}

\begin{abstract}
The voltammetric behavior of spontaneously adsorbing Mo layers on Pt( 111$)$ and $\mathrm{Pt}(100)$ electrodes has been studied to estimate the mumber of electrons involved in the electrochemical processes of spontaneously adsorbed Mo and the number of the blocked Pt sites for hydrogen adsorption. On Pt( 111$)$ and Pt( 100$)$ surfaces. the spontaneously adsorbed Mo layers showed redox peaks at $0.10 \mathrm{~V}$ and $0.15 \mathrm{~V}$. respectively, and contimuous current-potential waves in the conventional hydrogen region. Since the potential range of the Mo redox processes on both surfaces overlapped partially with the potential range of hydrogen adsorption, the variation in the ratio of the total charge of Mo and $\mathrm{H}\left(\mathrm{Q}_{\mathrm{H}}+\mathrm{Q}_{\mathrm{M}}\right)$ to the hydrogen charge of clean Pt electrode $\left(\mathrm{Q}_{\mathrm{H}}{ }^{\circ}\right)$ was analyzed. From the analysis. six electrons were estimated to be involved in the electrochemical processes of the spontaneously adsorbed Mo. and four Pt sites for hyddrogen adsorption were calculated to be blocked by one adsorbed Mo atom. Based on these figures and the $\mathrm{pH}$ dependence of the Mo redox processes. we have proposed an electrochemical equation for the spontaneously adsorbed Mo. This electrochemical equation led us to conclude that the saturation coverage of the spontaneously adsorbed Mo is 0.25 . The coverage of Mo less than 0.25 . however. could not be determined voltammetrically due to the convolution of the charges of Mo and $\mathrm{H}$.
\end{abstract}

Keywords : Mo. Adsorption, Pt(111), Pt(100), Voltammetry.

\section{Introduction}

In the research of fuel cells using Pt catalysts toward small organic molecules. the modification of electrode surfaces with foreign metal layers has been emphasized. ${ }^{1.2}$ The surface modification is carried out mainly by underpotential deposition ${ }^{3}$ and inmersion method. ${ }^{4-8}$

The two surface modification methods differ from each other in stripping behavior. In the underpotential deposition. a metal ion is deposited and stripped in a reversible manner $\left(\mathrm{M}(\mathrm{ad})-\mathrm{ne}^{-} \rightleftarrows \mathrm{M}^{\mathrm{n}+}(\mathrm{aq})\right.$ ). In the immersion method a metal ionic oxy'genated layer is produced spontaneously by simply immersing an electrode into a solution containing the metal ion $\left(\mathrm{M}^{\mathrm{n}-}(\mathrm{aq}) \rightarrow \mathrm{M}^{\mathrm{11}-}(\mathrm{ad})\right)$. The resulting ionic layer trpically shows a reversible redox behavior at a certain potential $\left(\mathrm{M}^{\mathrm{j}^{+}}(\mathrm{ad})+\mathrm{ne}^{-} \rightleftarrows \mathrm{M}(\mathrm{ad})\right)$, but strips irreversibly at a higher potential than the redox potential $\left(\mathrm{M}^{\mathrm{n}-}(\mathrm{ad}) \rightarrow \mathrm{M}^{\mathrm{I}^{\prime}}(\mathrm{aq})+\right.$ $\left(n^{\prime}-n\right) e^{-}$. where $\left.n^{\prime}>n\right)$. Because of the irreversibility in stripping the spontaneous adsorption is called irreversible adsorption.

The spontaneously adsorbed metallic layers of various elements ${ }^{5-22}$ were investigated extensively in conjunction with the oxidation of small organic molecules..$^{33-44}$ Specifically. it has been found that $\mathrm{Ru}$ and $\mathrm{Bi}$ modifiers enhanced dramatically the catalytic activity of $\mathrm{Pt}$ in methano ${ }^{30.40 .+1}$ and formic acid 3.24 .28 .93 .31 .33 .43 .44 oxidation. respectively. Although three mechanisms (electronic effect. third body effect and bifunctional effect) have been proposed, ${ }^{8}$ the actual enhancing mechanism concerning $\mathrm{Ru}$ and $\mathrm{Bi}$ were not

\footnotetext{
${ }^{*}$ Corresponding author. Tel: $+82-42-821-5483$ : Fax: +82-42-8231360: e-mail:ckrhee acnu.ac.k
}

clearly understood

On the other hand the characteristic electrochemical properties of a spontaneously adsorbed metal ionic layer itself cannot be negligible. For example. the spontaneously adsorbed layer of $\mathrm{Sb}$ became electrochemically inactive upon reduction. ${ }^{21}$ which was possibly caused by the lateral movement of the reduced $\mathrm{Sb}$ atoms. We have observed such a lateral movement of Te on Pt(111) with in-situ STM. ${ }^{45}$ In addition, we have found that the spontaneous adsorption and underpotential deposition take place sequentially or simultaneously in achieving a full monolayer of an irreversibly adsorbing metal ion. ${ }^{21.4 i}$ These observations clearly indicate that the electrochemical deposition of spontaneously adsorbed metal ion may be different from the conventional underpotential deposition.

In the present study. we present the electrochemical behavior of spontaneously adsorbed $\mathrm{Mo}$ on $\mathrm{Pt}(111)$ and $\mathrm{Pt}(100)$ single crystal electrodes. The main focus of this work is the estimation of the number of electrons involved in the electrochemical processes of spontaneously adsorbed Mo and the number of the blocked Pt sites for hydrogen adsorption.

\section{Experimental Section}

The platinum single crystal electrodes employed in the present work were prepared by the bead method. ${ }^{47} \mathrm{Pt}$ single crystal beads were produced by melting Pt wire (diameter $=0.5 \mathrm{mum}$. Aldrich. $99.99 \%$ ) in a hydrogen-oxygen flame and aligned to the desired direction using a home-built 3 dimensional goniometer and a $\mathrm{He}-\mathrm{Ne}$ laser. The aligned single cry stal beads were cut to reasonable surface areas and 
the crystal surfaces were polished down to $1 / 4 \mu \mathrm{m}$ to be mirror-like. A clean and ordered surface of $\mathrm{Pt}(\mathrm{lll})$ was routinely obtained after flame anuealing treatment. However. a well-defined surface of $\operatorname{Pt}(100)$ was obtained with the application of $50 \mathrm{~Hz}$ sawtooth wave between $-0.3 \mathrm{~V}$ and 0.7 $V$ after flanie arunealing treatment. ${ }^{48}$

The solutions used in this work were made of ultrapure water (> $18 \mathrm{M} \Omega \cdot \mathrm{cm}^{-1}$. Barnsted). $\mathrm{H}_{2} \mathrm{SO}_{4}$ (Merck. Suprapur) and $\mathrm{MoO}_{3}$ (Aldrich, 99.99\%). Particularly. the solution of Mo was obtained by saturating ultrapure water with $\mathrm{MoO}_{3}$ and the concentration of Mo was measured to be approximately $6 \mathrm{mM}$ of $\mathrm{MoO}_{3}$.

Voltanmetric studies were performed using a conventional three-electrode system. and the potentials reported in the present work are against to an $\mathrm{Ag} / \mathrm{AgCl}$ reference electrode whose chloride concentration was $1.0 \mathrm{M}$.

\section{Results and Discussion}

Figure 1 and 2 show the cyclic voltammograms of spontaneously adsorbed oxygenated Mo on Pt(111) and Pt(100) electrodes. respectively. After confurming well-ordered and clean surfaces of Pt single crystal electrodes, as shown in Figure l(a) and Figure 2(a), the electrodes were inmersed in the $\mathrm{MoO}_{3}$-saturated solution for approxintately 3 minutes without any applied potential to induce the spontaneous adsorption of Mo. Since a drop of the $\mathrm{MoO}_{3}$ containing solution was usually on the electrodes removed from the solution, the residual solution was completely rinsed with clean water. Then. the electrodes were brought into contact with $0.05 \mathrm{M}$ $\mathrm{H}_{2} \mathrm{SO}_{4}$ solution with the open circuit potential close to $0.7 \mathrm{~V}$.

Figure 1(b) and Figure 2(b) are the respective cyclic vol-

\section{(a)}
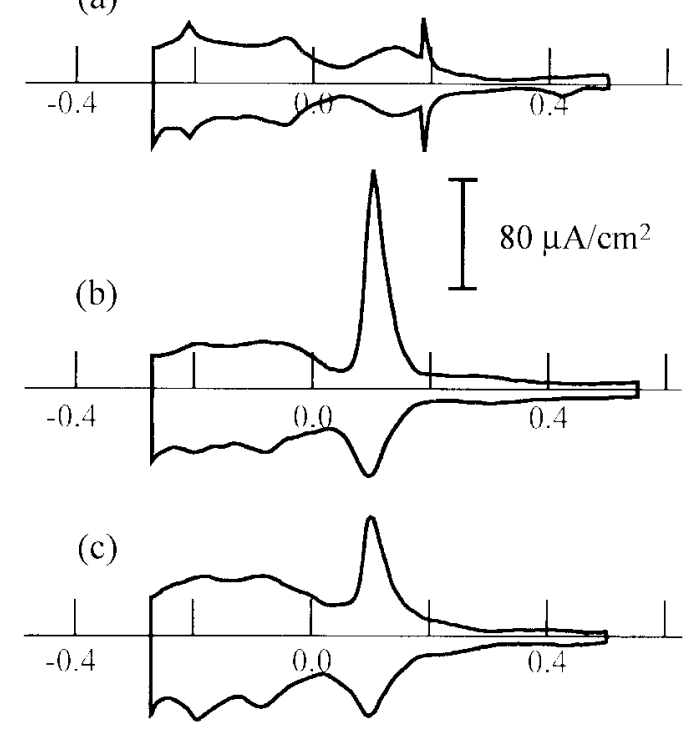

EV vs. $\mathrm{Ag} / \mathrm{AgCl}$

Figure 1. Cyclic voltammograms of $\mathrm{Pt}(111)$ in $0.05 \mathrm{M} \mathrm{H}_{2} \mathrm{SO}_{4}$ solution: (a) clean and ordered, (b) fully covered with spontancously adsorbed Mo and (c) partially covered with spontaneously adsorbed Mo. Scan rate: $50 \mathrm{mV} \cdot \mathrm{sec}^{-1}$. tammograms of $\mathrm{Pt}(11 \mathrm{l})$ and $\mathrm{Pt}(\mathrm{l} 00)$ saturated with spontaneously adsorbed oxygenated $\mathrm{Mo}$ in $0.05 \mathrm{M} \mathrm{H}_{2} \mathrm{SO}_{4}$ solution. The observed cyclic voltanmogranns of the spontaneously adsorbed oxygenated Mo on $\mathrm{Pt}(\mathrm{III})$ and $\mathrm{Pt}(\mathrm{l00})$ show their own characteristic distinguishing them from those of other spontaneously adsorbing metal ions. The most contrasting voltammetric feature of Mo was a reversible redox peak observed at the positive end of the hydrogen region with a broad current-potential wave similar to the hydrogen adorption desorption wave. On Pt(111). a redox peak was observed at $0.10 \mathrm{~V}$, whose reduction charge was smaller than the corresponding oxidation charge. Since the reverse situation was observed in the conventional hydrogen region (from $0.05 \mathrm{~V}$ to $-0.27 \mathrm{~V}$ ), the missing charge in the reduction process at $0.10 \mathrm{~V}$ might be observed in the potential range. Indeed, the reduction charge from $0.20 \mathrm{~V}$ to $-0.27 \mathrm{~V}$ was close to the oxidation charge in the same potential range. On Pt( 100$)$, the voltammetric behavior was similar to that observed on Pt(111). A single redox peak at $0.15 \mathrm{~V}$ was clearly observed. while several voltanmetric features in the hydrogen region were convoluted. Here again. the reduction charge from 0.30 $\mathrm{V}$ to $-0.27 \mathrm{~V}$ was identical to the oxidation charge.

Figure l(c) and Figure 2(c) are the cyclic voltammograms of $\mathrm{Pt}(1 \mathrm{ll})$ and $\mathrm{Pt}(\mathrm{l00})$ covered with under-saturated Mo layers. Adjusting the inmersion time and/or the concentration of $\mathrm{MoO}_{3}$-contaning solution led us to various surface concentrations of the spontaneously adsorbed Mo. Clearly shown in the voltammograns is that the charges of the redox
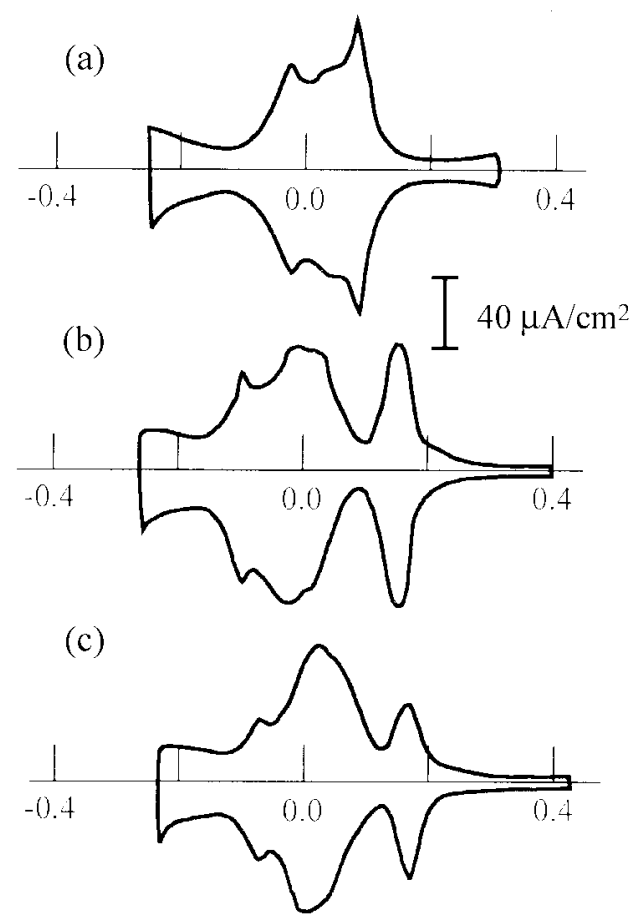

E/ v v. $\mathrm{Ag} / \mathrm{AgCl}$

Figure 2. Cyclic voltammograms of $\mathrm{Pt}(100)$ in $0.05 \mathrm{M} \mathrm{H}_{2} \mathrm{SO}_{4}$ solution: (a) clean and ordered, (b) fully covered with spontaneously adsorbed Mo and (c) partially covered with spontaneously adsorbed Mo. Scan rate: $50 \mathrm{mV} \cdot \mathrm{sec}^{-1}$. 
peaks at $0.10 \mathrm{~V}$ on $\mathrm{Pt}(111)$ and $0.15 \mathrm{~V}$ on Pt(100) decreased. These observations obviously indicate that the redox peaks are related to the spontaneously adsorbed Mo. On the other hand, the charges from the negative ends of the Mo redox peaks to the hydrogen evolution potential $(-0.27 \mathrm{~V})$ were measured to be constant within experimental error, regardless of the surface concentration of Mo. Specifically, the charges $\left(235 \pm 5 \mu \mathrm{C} / \mathrm{cm}^{2}\right.$ for $\mathrm{Pt}(111)$ and $208 \pm 0.5 \mu \mathrm{C} / \mathrm{cm}^{2}$ for $\left.\mathrm{Pt}(100)\right)$ are close enough to the theoretical hydrogen charges. i.e. 241 $\mu \mathrm{C} / \mathrm{cm}^{2}$ for $\mathrm{Pt}(111)$ and $209 \mu \mathrm{C} / \mathrm{cm}^{2}$ for $\mathrm{Pt}(100)$. Considering that the spontaneously adsorbed metal atoms generally block the Pt sites for hydrogen adsorption, ${ }^{9.25}$ the constancy of the charge in this particular potential region on both Pt electrodes implies that the reduced charge. resulting from inhibition of hydrogen adsorption by adsorbed Mo atoms, was compensated by the redox charge of Mo. As a result the charge in the conventional hydrogen region was constant. Therefore. it is logical to conclude that the electrochemical processes conceming hydrogen and Mo cannot be distinguished voltanmetrically.

The number of electrons transferred in the electrochemical processes of the spontaneously adsorbed Mo and the number of the hydrogen adsorption sites blocked by an adsorbed Mo atom can be estimated using voltammetric results based on the following equation:

$$
n_{\mathrm{Pt}}=n_{\mathrm{Pt}}{ }^{\circ}-n_{\mathrm{l}} \cdot n_{\mathrm{M} \mathrm{O}}
$$

where $n_{\mathrm{Yr}}, n_{\mathrm{Ft}}{ }^{\circ} . n_{\mathrm{b}}$ and $n_{\mathrm{No}}$ are the number of Pt atoms not blocked by Mo atoms. the number of Pt atoms on a clean Pt electrode surface, the number of Pt sites blocked by one Mo atom and the number of spontaneously adsorbed Mo atoms. respectively. After inserting $n_{\mathrm{t}}$ (the number of electrons transferred in electrochemical processes of the spontaneously adsorbed Mo) into equation (1). multiplying both sides by one electron charge will result in the following equation:

$$
\mathrm{Q}_{\mathrm{H}}=\mathrm{Q}_{\mathrm{H}}{ }^{\circ}-\left(n_{\mathrm{b}} / n_{\mathrm{t}}\right) \cdot \mathrm{Q}_{\mathrm{H}} \text {. }
$$

where $\mathrm{QH}_{\mathrm{H}} \mathrm{Q}_{\mathrm{vlo}}$ and $\mathrm{Q}_{\mathrm{H}}{ }^{\circ}$ are the charges for hydrogen and Mo on a Mo-covered Pt electrode. and the hydrogen charge of a clean Pt electrode. respectively. If one obtains $\mathrm{Q}_{\mathrm{H}}$ and Q Mo separately, the experimental value of $\left(n_{\mathrm{b}} / n_{\mathrm{t}}\right)$ can be easily estimated. In the present work, unfortunately. $\mathrm{Q}_{\mathrm{H}}$ and QMo cannot be measured separately as discussed before. When a Pt electrode is saturated with the spontaneously adsorbed Mo, i.e. $\mathrm{Q}_{\mathrm{H}}=0$. however, it is possible to determine the ratio of $\left(n_{\mathrm{b}} / n_{\mathrm{t}}\right)$. In this particular condition. equation (2) becomes as follows:

$$
\mathrm{Q}_{\mathrm{Mo}}{ }^{\mathrm{sat}} / \mathrm{QH}^{0}=n_{\mathrm{l}} / n_{\mathrm{b}} \text {. }
$$

where $\mathrm{QNo}$ sat is the saturation charge of Mo on a Pt electrode.

Figure 3 shows the variation of $\left(\mathrm{Q}_{\mathrm{H}}+\mathrm{Q}_{\mathrm{No}}\right) / \mathrm{Q}_{\mathrm{H}}{ }^{\circ}$ as solution exposure changes. Since the surface concentration of the spontaneously adsorbed Mo was adjusted with inmersion time and/or the concentration of Mo, solution exposure was defined as the product of concentration and immersion time $(\mathrm{mM} \cdot \mathrm{sec})$, which is analogous to the unit of Langmuir $\left(\mathrm{L}=10^{-6}\right.$ Torr $\left.\cdot \mathrm{sec}\right)$ for gas exposure in UHV experiments.

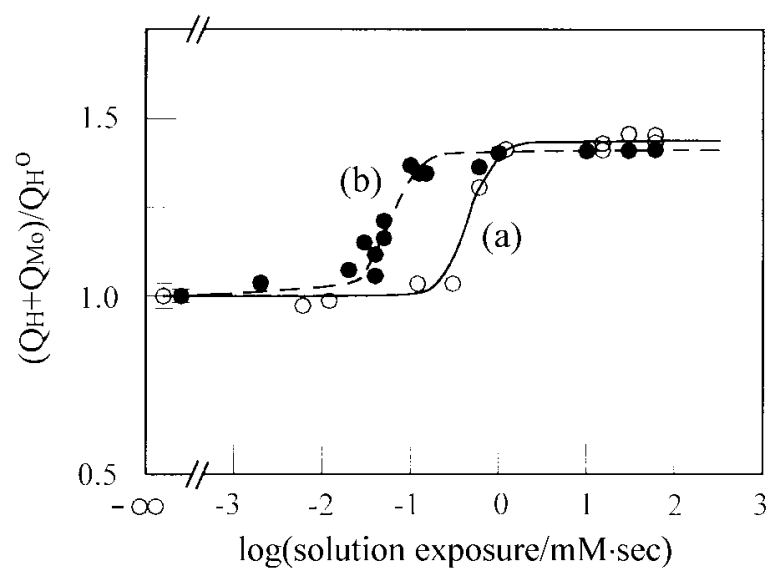

Figure 3. Variation in the ratio of the total charge of $\mathrm{Mo}$ and $\mathrm{H}$ $\left(\mathrm{Q}_{\mathrm{H}}+\mathrm{Q}_{\mathrm{M}}\right)$ to the hydrogen charge $\left(\mathrm{Q}_{\mathrm{H}}{ }^{\circ}\right)$ of clean Pt electrode: (a) $\mathrm{Pt}(11 \mathrm{l}$ ) (open circle) and (b) $\mathrm{Pt}(\mathrm{IO0})$ (filled circle). See the text for the details of solution exposure.

$\left(\mathrm{Q}_{\mathrm{H}}+\mathrm{Q}_{\mathrm{Mo}}\right)$ is the charge from $0.20 \mathrm{~V}$ to $-0.27 \mathrm{~V}$ for $\mathrm{Pt}(11 \mathrm{l})$ and $0.30 \mathrm{~V}$ to $-0.27 \mathrm{~V}$ for $\mathrm{Pt}(100)$. respectively, after subtracting a capacitive charge. At low solution exposure, the value of $\left(\mathrm{QH}_{\mathrm{H}}+\mathrm{QMd}_{\mathrm{No}}\right) / \mathrm{QH}_{\mathrm{H}}$ - remained close to 1 , which indicates that no adsorption of Mo occurs $\mathrm{Q}_{\mathrm{Mu}} \approx 0$ ). The spontaneous adsorption started taking place on $\mathrm{Pt}(\mathrm{III})$ and Pt $(100)$ when the solution exposure was approximately 0.3 and $0.03 \mathrm{mM} \cdot \mathrm{sec}$, respectively. Then, the ratios observed on $\mathrm{Pt}(11 \mathrm{l})$ and $\mathrm{Pt}(100)$ at high solution exposure, i.e. $\mathrm{Q}_{\mathrm{co}}^{\text {sat }}$ $\mathrm{Q}_{\mathrm{H}}{ }^{\circ}$. converged to $1.48 \pm 0.030$ and $1.41 \pm 0.004$, respectively.

Table 1 shows possible combinations of $n_{\mathrm{t}}$ and $n_{\mathrm{t}}$, and the ratios of $n / n_{\mathrm{t}}$. The calculated ratio closest to the experimentally determined ratios ( 1.48 for $\mathrm{Pt}(11 \mathrm{l})$ and $1.4 \mathrm{l}$ for $\mathrm{Pt}(100)$ ) is 1.50. which implies that six electrons are involved in the electrochemical processes of the spontaneously adsorbed Mo and that a single adsorbed Mo atom blocks four Pt sites for hydrogen adsorption. In addition to these, $60 \mathrm{mV} / \mathrm{pH}$ dependence of the spontaneously adsorbed Mo indicates that protons are involved in the redox processes of Mo and that the number of protons is equal to the number of electrons. Based on these results. we propose the following electrochemical equation:

$$
\begin{aligned}
& \text { oxygenated } \mathrm{Mo} \text { (VI. aq) } \rightarrow \\
& \mathrm{MoO}_{3}(\mathrm{VI}, \mathrm{ad})+6 \mathrm{H}^{+}+6 \mathrm{e} \rightleftarrows \mathrm{Mo}(0 . \mathrm{ad})+3 \mathrm{H}_{2} \mathrm{O}
\end{aligned}
$$

From this equation, the saturation coverages of Mo (defined as the ratio of Mo atoms to $\mathrm{Pt}$ atoms) were calculated to be 0.25 and 0.24 for $\mathrm{Pt}(111)$ and $\mathrm{Pt}(100)$. respectively.

One may argue that the involvement of three electrons in the electrochemical processes of the spontaneously adsorbed

Table 1. Possible combinations of the number of electrons transferred in electrochemical processes of the spontaneously adsorbed Mo $\left(n_{1}\right)$ and the number of Pt atoms blocked by one Mo atom $\left(n_{k_{1}}\right)$

\begin{tabular}{cccccc}
\hline$n_{\mathrm{t}}$ & 4 & 5 & 5 & 6 & 6 \\
$n_{\mathrm{b}}$ & 3 & 3 & 4 & 4 & 5 \\
$n_{n_{\mathrm{b}}} / n_{\mathrm{b}}$ & 1.33 & 1.67 & 1.25 & 1.50 & 1.20 \\
\hline
\end{tabular}


Mo and the blockage of two Pt sites for hydrogen adsorption may be another possible combination accounting for the measured ratio of $n_{t} / n_{\mathrm{b}}$. In such a case. the saturation coverage of Mo turns out to be 0.5 , which is too large. Saturation coverages of spontaneously adsorbing oxygenated metal ions. when only spontaneous adsorption is carried out. span generally from 0.33 to 0.25 .

One more thing to be addressed is that the impossibility of measuring voltanmetrically the coverage of Mo less than 0.25 . The reason for this is that the redox peaks of Mo cannot be separated from the redox waves of hydrogen in the conventional hydrogen region. Therefore, other techniques. like electron spectroscopy and scanning probe microscopy. should be employed to measure the Mo coverage below 0.25 .

\section{Conclusions}

The voltanmetric behavior of spontaneously adsorbing Mo on $\mathrm{Pt}(111)$ and $\mathrm{Pt}(100)$ electrodes was studied to estimate the number of electrons involved in the electrochemical processes of spontaneously adsorbed Mo and the number of blocked Pt sites for hydrogen adsorption. The spontaneously adsorbed Mo layers on both surfaces showed respective redox peaks at the positive end of the conventional hydrogen region and continuous voltanmetric waves down to the hydrogen evolution potential. Since it was impossible to measure the charge concerning Mo only, the variation in the ratio of the total charge of Mo and $\mathrm{H}$ to the hydrogen charge on a clean Pt electrode was analyzed as the solution exposure (defined in this work) changed. From the analysis. six electrons were estimated to be involved in the electrochemical processes of the spontaneously adsorbed $\mathrm{Mo}$. and four Pt sites for hydrogen adsorption were calculated to be blocked by one adsorbed Mo atom. Based on these figures and the $\mathrm{pH}$ dependence of the Mo redox processes, we have proposed an electrochemical equation for the spontaneously adsorbed Mo. In turn. this electrochemical equation has led us to conclude that the saturation coverage of the spontaneously adsorbed Mo is 0.25 . The coverage of Mo less than 0.25 , however. was inpossible to determine voltammetrically due to the convolution of the charges of $\mathrm{Mo}$ and $\mathrm{H}$.

\section{References}

1. Kokkinidis. G. J. Elechoanal. Chem. 1986. 201, 217.

2. Adzic. R. R. In Achances in Electrochentistry and Electrochemical Engineering. Gerischer. H.. Tobias. C. W. Eds: Wiley: New York. 1984: vol. 13.

3. Conway B. E. Prog. Surf. Sci. 1984. 16, 1 and references therein.

4. Janssen. M. M. P.: Moolhuysen. J. Elechochm. Acta 1976, 21. 861.

5. Janssen. M. M. P.: Moolhuysen. J. Electrochim. Acta 1976. 21. 869

6. Motoo. S.: Shibata. M. J. Electromal. Chem. 1982. 139. 119.

7. Shibata M.: Motoo. S. J. Electroanal. Chem. 1985, 188. 111.

8. Parsons, R.: VanderNoot. T. J. Electroamal. Chem 1988. 257.9.

9. Clavilier. J.: Feliu. J. M.: Aldaz. A. J. Electronfal. Chem. 1988. $2+3.419$.
10. Feliu. J. M.; Fernandez-Vega, A.; Aldaz, A.; Clavilier, J. J. Electroomal. Chent 1988. 256. 149.

11. Clavilier. T.: Feliu. I. M.: Fernandez-Vega. A.: Aldaz. A. J. Electromal. Chent 1990. 294. 193.

12. Clavilier. J; Orts. J. M.: Feliu, J. M: Aldaz. A. J. Electroand Chem 1990, 293, 197.

13. Attard. G. A.; Bannister. A. J. Electroand. Chem. 1991. 300,467

14. Clavilier. T.: Llorca. M. J.: Feliu. J. M.: Aldaz. A. J. Electroanal. Chent 1991.310 .429 .

15. Feliu. T. M.: Fernandez-Vega. A.: Orts. T. M.: Aldaz. A. J. Chim. Phys. 1991, 88, 1493.

16. Feliu. J. M.: Gomez. R; Llorca. M. J.: Aldaz. A. Surf. Sci. 1993. 289. 152.

17. Feliu. T. M.: Llorca. M. T.: Gomez. G.: Aldaz. A. Sinff Sci. 1993. 297. 209.

18. Llorca. M. T.: Feliu. J. M.: Aldaz. A. J. Electroanal Chent 1993. 351.299.

19. Orts. J. M:; Rodes, A.: Feliu, J. M. J. Electroand. Chem. 1997. 434. 121 .

20. Chrzanowski. A.: Wieckowski. A. Langnuir 1997. 13. 5974.

21. Ju11. G.: Park. H.: Rhee. C. K. J. Electromal Chent 1998. +53. 243.

22. Smith. S. P. E.: Abruna. A. D. J. Phys. Chem. B 1998, $102,3506$.

23. Clavilier. J.: Femandez-Vega, A.: Feliu. J. M.: Aldaz, A. J. Electroand. Chem. 1989, 258. 89.

24. Clavilier. J.: Fernandez-Vega. A.: Feliu. J. M.: Aldaz. A. J. Electromal Chen. 1989.261. 113.

25. Femandez-Vega. A.: Feliu. T. M.: Aldaz. A. J. Electrounal. Chem 1989. 258,101

26. Fernandez-Vega. A.; Feliu, J. M.; Aldaz. A.: Clavilier, J. J. Electroanal. Chem. $1991,305.229$.

27. Chang. S.-C.: Weaver. M. J. Strf. Sci. 1991. 2H1. 11.

28. Chang. S.-C.: Ho. Y.: Weaver. M. T. Suff Sci. 1992. 265. 81

29. Herrero. E.: Fernandez-Vega. A.: Feliu. J. M.: Aldaz. A. J. Electromal. Chem $1993,350.73$

30. Herrero. E.: Franaszezuk. K.: Wiechowski, A. J. Electroanal. Chem $1993,361,269$.

31. Herrero. E.: Feliu. J. M.: Aldaz. A. J. Electroanal Chent 1994. 368. 101.

32. Llorca. M. T.: Feliu. J. M.: Aldaz. A.: Clavilier. J. J. Electroanal. Chem. 1994, 376, 151.

33. Kizhakevariam. N. Weaver, M. J. Suf. Sci. 1994. 310. 183.

34. Herrero. E; Rodes, A.; Perez. J. M.: Feliu, J. M.; Aldaz, A. d. Electromal. Chem. 1995.93.87.

35. Herrero. E.: Llorca. M. T.: Feliu. J. M.: Aldaz. A. J. Electroanal. Chent. 1995. 383. 145 .

36. Herrero. E.; Llorca, M. J.: Feliu. J. M: Aldaz. A. J. Electroanal. Chem. 1995, 394, 161.

37. Llorea. M. J:- Herrero, E.: Feliu. J. M: Aldaz. A. J. Electroanal. Chent. 1995. 373. 217.

38. Herrero. E.: Rodes. A.: Perez. J. M.: Feliu. J. M.: Aldaz. A. J. Electroanal. Chent 1996. H12. 165

39. Leiva. E.: Iwasita, T.: Herrero, E.; Feliu, J. M. Langmuir 1997, 13 . 6287.

40. Chrzanowski. W: Wieckowski. A. Catal Letters 1998, 50,69.

41. Chizanowski. W. Wieckowski. A Langmii 1998. 14. 1967.

42. Climent. V: Herrero. E.: Feliu. J. M. Electrohm. Acta 1998. H. 1403.

43. Smith. S. P. E.: Abruna, A. D. J. Electroanal. Chem. 1999. 467. 43 .

4. Smith. S. P. E.: Ben-Dor. K. F.: Abruna. A. D. Langmir $2000,16$. 787.

45. Rhee. C. K.: Kim. D. K. J. Electroanal Chem, 2001. 506.149.

46. Jung. G.: Rhee. C. K. J. Electroanal Chem 1997. 436. 277.

47. Clavilier. J.: Faure, R.: Guinet. G.; Durand, R. J. Electroamal. Chem $1980,107,205$.

48. Clavilier. J.: Amand. D. J. Electroanal. Chem. 1986, $199,187$. 